\title{
EFFECTS OF PATIENT COUNSELING ON DRUG DOSE REGIME AND MEDICATION COMPLIANCE IN ASTHMA PATIENTS: A PROSPECTIVE STUDY
}

\author{
SHIPRA OMAR*, ROHIT BANGWAL, SAHIL SHARMA, PRASHANT MATHUR
}

Department of Pharmacy Practice, School of Pharmaceutical Sciences, Shri Guru Ram Rai University, Shri Mahant Indiresh Hospital, Dehradun, Uttarakhand, India. Email: shipra.omar.28@gmail.com

Received: 10 April 2021, Revised and Accepted: 01 June 2021

\section{ABSTRACT}

Objectives: The objective of study is to estimate the role of counseling on the diseased patients with asthma and its effects on the medication adherence in relation to their associated side effects on medicines on patients.

Methods: The prospective case-control study was carried out at the outpatient department of respiratory department. 190 patients were enrolled for the study of 6 months. Patient counseling and follow-up were done on the basis of knowledge, attitude, and practice (KAP) questionnaire. In 190 subjects, 115 were female and 75 were male and were having the pathological history of cough cold, tuberculosis, hypertension, etc.

Results: It was found that counseling causes increase in medication adherence of patients from $28.90 \%$ to $71.50 \%$ and inhaler adherence from $27.60 \%$ to $72.60 \%$. Along with the medication adherence, fewer side effects due to various drugs were encountered such as sore throat, rhinitis, constipation, difficulty in glutition, hand tremor, and weight gain.

Conclusion: The study concluded that, patient counseling plays an important role in diseases like asthma, which changes the attitude, increases the knowledge which turns out into the better medication results improving the asthmatic symptoms.

Keywords: Questionnaire, Adherence, Glutition, Rhinitis, Hand tremor, Knowledge attitude practice.

(C) 2021 The Authors. Published by Innovare Academic Sciences Pvt Ltd. This is an open access article under the CC BY license (http://creativecommons.org/ licenses/by/4.0/) DOI: http://dx.doi.org/10.22159/ajpcr.2021v14i7.41766. Journal homepage: https://innovareacademics.in/journals/index.php/ajpcr

\section{INTRODUCTION}

Patient counseling is the inter-personal communication occurs between the pharmacist or a health care professional and a patient, deals with the transmission of information to the patient about their diseased condition, their medication pattern in the précised format which can be oral of written [1].

The main goal of patient counseling is to motivate the patients for adherence to their drug regime, and to develop the ability to take decisions regarding the adherence to their medication for effective treatment [2]

According to Society of Hospital Pharmacists of Australia (2004), pharmacist possesses the responsibility to comprehend the patients to make them able to adhere on the medication regime and make them informed for the use of medicines [3]. According to Beers et al. (1999), "the psychological, physical, and social realm of health found to be seen in various areas influenced by the experiences, faith, perception, and expectation of any individual" [4].

According to American Academy of Allergy, Asthma and immunology (2009), asthma is a reversible obstruction of airway stimulates by the various stimuli [5,6]. Asthma is the major inflammatory disorder of airways having a kingpin role of various cells and cellular elements, mainly mast cells, eosinophils, T-lymphocytes, macrophages, neutrophils, and epithelial cells [7]. Asthma attack which results in narrowing of airways than normal conditions makes the respiration difficult [8]. Management needs lifelong treatment for asthma. As it is a reversible disease, on a small relieve in asthmatic symptoms patients get non adhere to the medication, due to which patient counseling is required to provide the adequate information regarding the adherence of dosage $[9,10]$. According to Meshal et al.; (2015), patient counseling plays key role in the health-care system for the finer therapeutic results which results in decrease in drug related issues in patients [11]. According to Alotaibi et al.; (2016) the expertise of pharmacists in medications and due to their accessibility to patients may ensure positive outcomes on the disease [12]. The main aim of the study is to estimate the role of counseling on the diseased patients with asthma and its effects on the medication adherence in relation to their associated side effects on medicines on patients [13].

\section{METHODS}

\section{Study design}

The present prospective study was carried out in year 2017 at the outpatient department of respiratory department, in SMI Hospital, Patel Nagar, Dehradun. It is a 1000 bedded multispecialty hospital. The study was approved by hospital ethical committee and institutional ethical committee.

\section{Study duration}

The time period of study was 8 months. It includes the medication counseling procedure along with proper follow-up of patients.

\section{Sample size}

A total number of 190 patients were enrolled for the study.

\section{Patient consent}

Patient consent forms were produced and taken from all enrolled patient.

\section{Patient's enrollment}

They were enrolled on the basis of inclusion and exclusion criteria.

\section{Inclusion criteria}

The following criteria were included in the study:

- Patients of age 18-65 years

- Patients with airways inflammation disease, that is, asthma

- Patients with both male and female gender. 
Exclusion criteria

The following criteria were excluded from the study:

- $\quad$ Patients with age $>65$ years and $<18$ years

- Patients with other respiratory infection

- Pregnant patients

- Patients with HIV, hepatic, and renal disease.

\section{Study procedure and data collection}

A patient profile format was prepared for patients' record and the followup study. A knowledge, attitude, and practice (KAP) questionnaire was prepared. Moreover, to it, a leaflet was prepared in both English and Hindi to make patients more comprehend about the disease.

Patients diagnosed with bronchial asthma were taken in the observation. The questionnaire was filled according to their assessment on basis on KAP. The questionnaire was having two parts. First part consists of the demographic details of patients including their name, age, gender, and socio-economic conditions and the second one consist of 11 questions related to their diseased condition. Few questions were optional while few were about the answers in yes or no. An average of 15-20 min was taken with the patients to comprehend the lingual and educational status of the patients. Written and diagrammatic methods were used to make patients understood about the disease and antiasthmatic medication along with the diet to have and the diet to avoid during the medication period.

\section{Statistical analysis}

The data entry and analysis were done using statistical graphical presentation.

\section{RESULTS}

Assessment of patients before counseling

A total number of 190 diagnosed asthmatic patients were enrolled according to the inclusion criteria. In this study, 75 (34.97\%) patients were male and 115 (60.5\%) patients were female. A majority of subjects $56(29.6 \%)$ were of age group between 25 and 35 years were affected with asthma (Table 1).

A high number of patients including both female and male were smokers, $101(53.2 \%)$. About 56 (29.5\%) patients were having tobacco habits. Moreover, 13 (12.46\%) patients were alcoholics. In total 190 patients, $65(34.2 \%)$ were vegetarians and about $125(65.8 \%)$ patients were non-vegetarians (Fig. 1).

A majority of patients $31.05 \%$ were affected with history of cold and cough like symptoms. And about $12.7 \%$ patients were affected with hypertension. About $16.31 \%$ patients reported the problem of seasonal allergy. In 190 patients, about $5.78 \%$ and $3.15 \%$ patients reported the medical problem of tuberculosis and rhinitis, respectively (Fig. 2).

Furthermore, most patients 102 (53.68\%) reported no specific family history of asthma. Only few patients, $23(12.10 \%)$ and 29 (15.26\%) reported the asthmatic the history of their mother and father, respectively (Fig. 3)

On further findings, it was found that, out of 190 patients, 126 (66.3\%) patients experienced the asthmatic symptoms all the day. 64 (33.7\%) patients experienced the symptoms sometime during the seasonal change, or coming in contact with the allergens (Table 2).

Regarding the prescription patterns of patients, the most common drugs were prescribed to them, methylxanthines and inhalational corticosteroids were prescribed to $10.52 \%$ patients, long acting beta agonist and anticholinergic drugs were prescribed to $29.74 \%$ patients, short acting beta agonists along with inhaled corticosteroids were prescribed to $16.31 \%$ patients, and mast cell stabilizers along with inhaled corticosteroids and expectorants were prescribed to $10.1 \%$ patients, respectively (Fig. 4).
Table 1: Distribution on the basis of demographic data

\begin{tabular}{ll}
\hline Demographic factors & No of patients (\%) \\
\hline Gender & $75(34.9)$ \\
Male & $115(60.5)$ \\
Female & \\
Age (years) & $29(15.3)$ \\
$15-25$ & $56(29.5)$ \\
$25-35$ & $38(20.0)$ \\
$35-45$ & $44(23.2)$ \\
$45-55$ & $23(12.1)$ \\
$55-65$ & $65(34.2)$ \\
Diet habits & $125(65.8)$ \\
Vegetarians & \\
Non-Vegetarians &
\end{tabular}

Table 2: Distribution on the basis of arousal of symptoms

\begin{tabular}{ll}
\hline Symptoms & No. of patients (\%) \\
\hline All the day & $126(66.3)$ \\
Seasonal, due to allergens & $64(33.7)$ \\
\hline
\end{tabular}

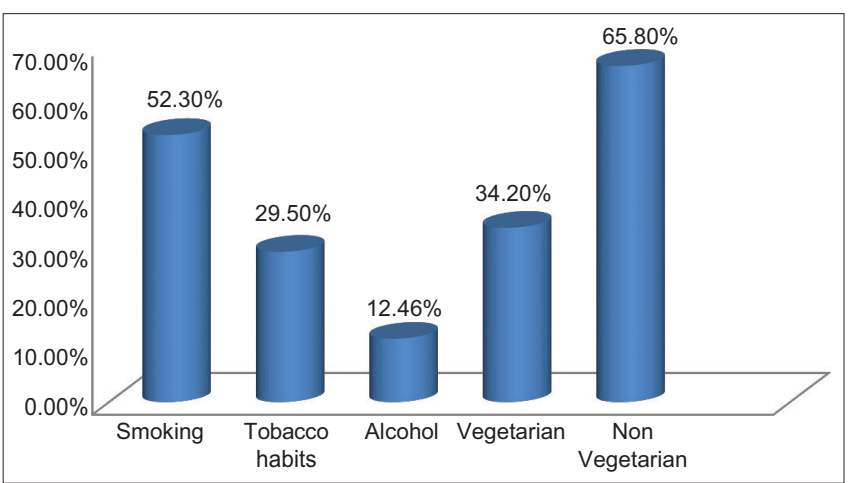

Fig. 1: Distribution on the basis of social habits

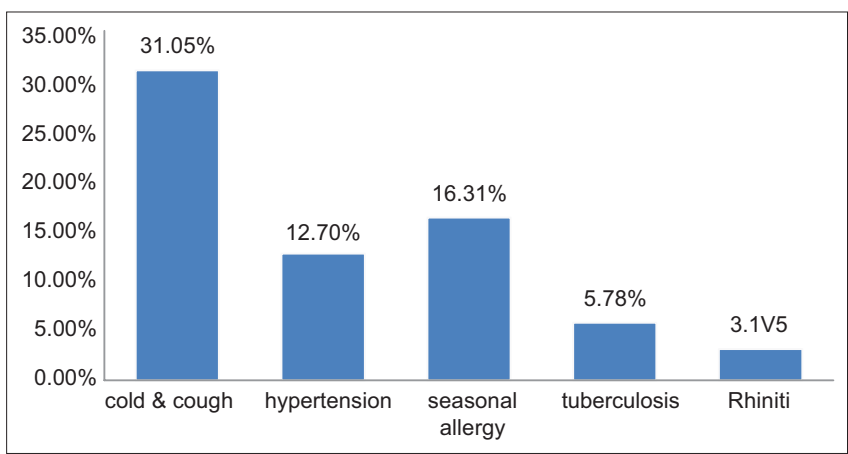

Fig. 2: Distribution on the basis of medical history

Furthermore, out of 190 patients, 55 (28.9\%) patients were taking regular medicine, and about $135(71.5 \%)$ patients were taking medicines irregularly and $52(27.6 \%)$ patients were using inhaler regularly as per doctors' advice and $138(72.6 \%)$ patients were taking irregular dosing and at irregular time according to onset and frequency of symptoms as per their prescribed regime.

Assessment of patients post counseling using KAP questionnaire Asthma is a most common allergic condition which symptoms increases with various stimuli such as change in weather, contact with pet fur, pollen grains, dust, and pollution and may evoke genetically from mother and father. On the basis of investigation on the basis of details given by the patients the above reports were assessed. During the research study, it was 


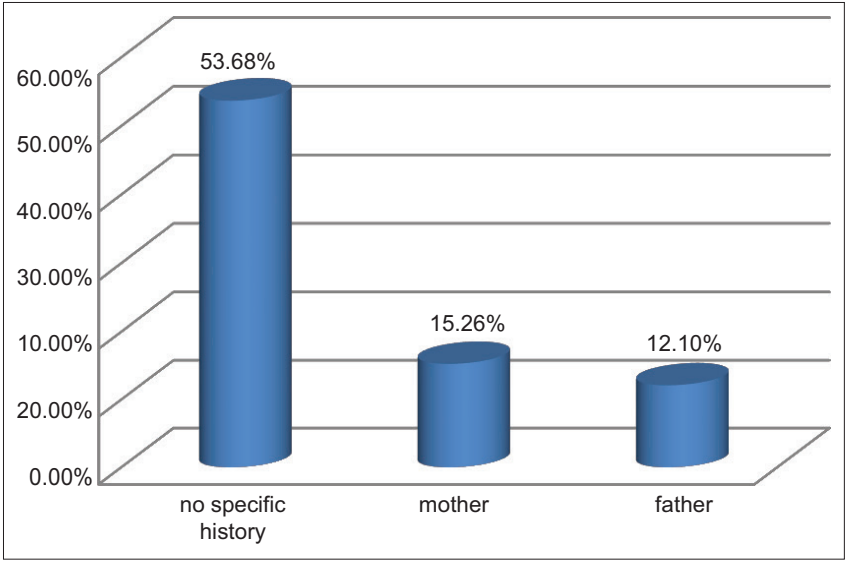

Fig. 3: Distribution on the basis of family history

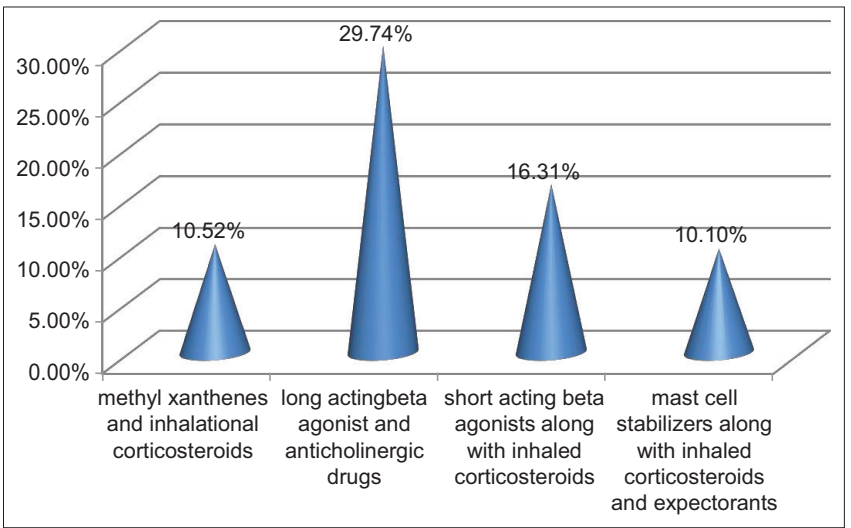

Fig. 4: Distribution of patients on the basis of prescription pattern

found that, most of the patients were not having the correct information about the disease. Patient counseling has become the key point to improve the patient's quality of life and for the pharmaceutical care too. The knowledge of patients was assessed on the basis of questionnaire. And then they were counseled on the basis of medication patterns and they were advised to visit hospital weekly for the proper follow-up. Day to day follow-up was done by telephonic conversations. Finally, it was found into the study that there was an improvement in the medication patterns and the use of inhalers on the patients' lifestyle showing positive outcomes. Primarily patients were not aware of the related sudden effects and adverse drug event during the medication therapy. Later on, on regular use of medications and inhalers on prescribed regime various drug related events and side effects were reported, given below (Fig. 5).

\section{DISCUSSION}

Asthma is a common condition of airway inflammation affecting a large population day by day. According to Gaur et al., the prevalence of asthma in adults' population is found to be $11.03 \%$, and a strong variation has been shown between children, that is, $4-19 \%$ in Asian population [14]. Asthma is more frequently seen among female than male. In our study, $60.52 \%$ subjects were female than $39.47 \%$ male. The most expedited drugs in asthma were long acting beta adrenergics with methylxanthines, and anticholinergics, that is, $29.74 \%$. Other preferable drugs were about $16.31 \%$ short acting beta adrenergics with inhalational corticosteroids and $15.26 \%$ long acting beta adrenergics with inhaler corticosteroids, respectively.

In the present study, it was found that the patient compliance has increased for medication and inhaler use after questionnaire and information-based counseling. The regular use of inhaler and medicine gradually increased from $27.6 \%, 28.5 \%$ to $61 \%$, and $57.5 \%$, respectively.

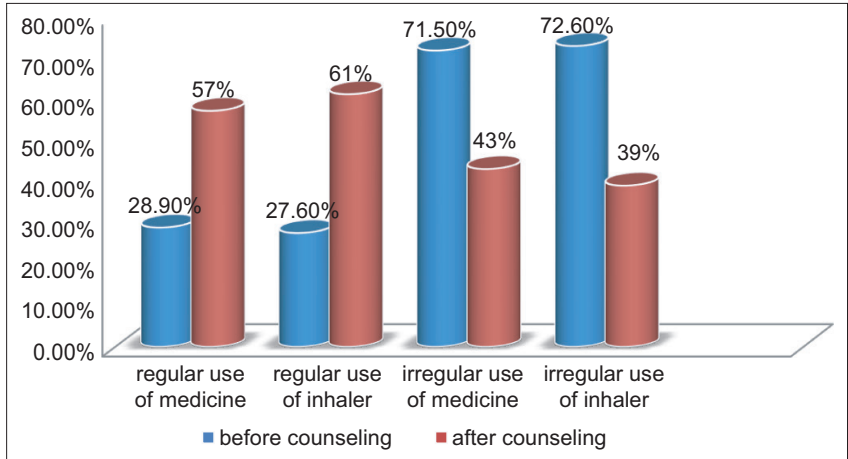

Fig. 5: Distribution on the basis of comparison between the use of medicines and inhalers pre- and post-counseling

\section{CONCLUSION}

- Patient counseling plays an important role in diseases like asthma, which changes the attitude, increases the knowledge which turns out into the better medication results improving the asthmatic symptoms

- Patient compliance is necessary for any diseased condition leads to maintain the quality of life of patient

- By better compliance, leads to decrease in symptoms which ultimately lower the over usage of drugs and inhalers

- By accurate adherence, various adverse events and adverse reactions may be reported which may result in change in prescribed drugs therapy, if prevailed for long time

- A new adverse effect can also be thus reported

- Thus, patient counseling helps in many broad ways to improve the quality of patients' life and decrease the severity of symptoms.

\section{ACKNOWLEDGMENT}

The authors wish to thank the HOD sir, Faculty Members of Department of Pharmacy Practice, Shri Guru Ram Rai University, and the Head of Department of Respiratory Department, and doctors of Shri Mahant Indresh Hospital, Dehradun, for their positive support to complete the research work.

\section{AUTHORS CONTRIBUTION}

We thank all the authors for their help at various levels in the smooth conduction of this research work, data collection, and preparation of the manuscript.

\section{CONFLICT OF INTEREST}

The authors have no conflicts of interest.

\section{AUTHORS FUNDING}

The research work has the no funding from any funding agencies.

\section{REFERENCES}

1. Anupa KC, Durga B, Subish P, Mishra P. Patient counseling by pharmacists: A novel approach to enhance patient compliance. J Nep Pharm Assoc 2005;23:17-22.

2. Ramesh A. Patient counseling. In proceedings: National seminar on advances in industrial pharmacy and pharmacy practice. JSS Coll Pharm J 1999;44:82-8.

3. Masoli M, Fabian D, Holt S, Beasley R. The global burden of asthma: Executive summary of the GINA dissemination committee report. Eur J Allergy Clin Immunol 2004;59:469-78.

4. Beers MH, Berkow R. The Merck manual of diagnosis and therapy. Merck Res Lab New J 1999;17:40-1.

5. Kudo M, Ishigatsubo Y. Introduction to asthma American academy of allergy. Asthma Immunol Am J Respir Crit Care 2013;188:7-8.

6. Self TH, Rumbak MJ, Kelso TM. Correct use of metered-dose inhalers and spacer devices. Postgrad Med J 1992;92:95-6. 
7. Cockcroft DW. Practical issues in asthma management: Correct use of inhalation devices. Ann Allergy J 1993;71:83-4.

8. Meshal A, Sarriff A, El-Shamly M. Pilot testing of a pharmacist led care program for asthma patients in Saudi Arabia. Saudi Pharm J 2015;23:210-4.

9. Alotaibi HS, Shivanandappa TB, Nagarethinam S. Contribution of community pharmacists in educating the asthma patients. Saudi Pharm J 2016;24:685-8.

10. Ramesh A, Sathyanarayana V, Rajini M, Ranjini V. Evaluation of the impact of a therapeutic management and effect of pharmacist intervention on children with asthma. Indian J Pharm Pract 2011;14:39-48.

11. Gaur SN, Gupta K, Rajpal S, Singh AB, Rohatgi A. Prevalence of bronchial asthma and allergic rhinitis among urban and rural adult population of Delhi. Indian J Allergy Asthma Immunol 2013;2:90-7.

12. Kamfar HZ, Koshak EE. The impact of some demographic factors on the severity of asthma in children. J Family Community Med 2002;9:19-24

13. Gupta S, Awasthi S. Assessment of treatment pattern of childhood asthma reporting to outpatient's facility in a tertiary care hospital in Lucknow, North India: A cross-sectional study. Clin Epidemiol Glob 2016;4:6-11

14. Schatz M, Hsu JW, Zeiger RS, Chen W, Dorenbaum A, Chipps BE, et al. Phenotypes determined by cluster analysis in severe or difficultto-treat asthma. J Allergy Clin Immunol. 2014; 133:1549-56. 